\title{
La sentencia del certamen poético de Sant Just (1438): edición y estudio preliminar*
}

\author{
The sentence of the Sant Just poetical contest (1438): edition and \\ preliminary study
}

\author{
SADURní MarTí \\ sadurni.marti@udg.edu \\ ILCC - Universitat de Girona
}

Resumen: En este trabajo se publica por primera vez la sentencia de un concurso poético medieval celebrado en la iglesia Barcelonesa de Sant Just en junio de 1438. El tema elegido para la ocasión fue el maldecir de Amor y la joya fue ofrecida por Bartomeu Castelló. Sabemos que a él concurrieron Guillem y Joan Berenguer de Masdovelles. Lo sorprendente de esta sentencia reportada por el Cancionero del Marqués de Barberà es que, no sólo presenta el discurso-sermón inicial (con un sorprendente diálogo casi teatralizado), sino también una glosa de las piezas presentadas, en un texto que alterna catalán y latín.

Palabras clave: Consistori, Poesía de certamen, Masdovelles, Cançoners

Abstract: This paper edits for the first time the sentence of a medieval poetical contest celebrated at the Sant Just church of Barcelona, in June 1438. The chosen thema was the lament against Love and the jewel to be awarded was offered by Bartomeu Castelló. We know the poets Guillem and Joan Berenguer de Masdovelles participated. The most remarkable aspect of this verdict, written in Catalan and Latin, and copied in the songbook of the Marquis of Barberà, is that not only presents the starting speech-preaching (which includes a para-theatrical dialogue), but also a commentary of the pieces that competed.

Keywords: Consistori, Contest poetry, Masdovelles, Songbooks.

\footnotetext{
* Este artículo es la versión corregida y aumentada de una comunicación presentada en el II Congreso Internacional de la Sociedad de Estudios Medievales y Renacentistas, celebrado en San Millán de la Cogolla en septiembre de 2008. Se inscribe en el cuadro de los proyectos de investigación Mecenazgo y creación literaria en la corte catalano-aragonesa (siglos XIIIXV): evolución, contexto y biblioteca digital de referencia (MEC FFI2014-53050-C5-5-P) y Troubadours and European Identity: The Role of Catalan Courts (Recercaixa 2015 ACUP 00127) del Institut de Llengua i Cultura Catalanes de la Universitat de Girona. Quisiera dejar constancia de mi agradecimiento a Miriam Cabré, Alejandro Coroleu, Rafael Ramos, Jaume Riera i Sans, Jaume Torró y Verónica Zaragoza por sus comentarios y sugerencias durante la elaboración de este trabajo.
} 
0. Entre los folios 145v-150r del Cancionero del Marqués de Barberà (Montserrat, Biblioteca del Monasterio, ms. 991; cancionero catalán $S^{1}$, castellano BM1) ha pasado desapercibida la copia de un discurso, hasta hoy inédito, relacionado con un certamen poético convocado en la iglesia de Sant Just de Barcelona en 1438. Es un texto insólito, tanto por su contenido como por su estado de redacción fragmentario, quizás porque sea la copia del borrador de un discurso a la espera de la redacción definitiva. ${ }^{1}$ El cancionero bilingüe donde se halla se compiló durante la década de 1470 y reúne obras producidas, en catalán y castellano, entre 1438 y 1474. La organización interna del manuscrito no sigue ningún criterio ni cronológico ni temático, sino que responde más a la sucesiva accesibilidad de materiales, que a un diseño previo (Martí 1997). Uno de sus aspectos destacables es la presencia de un grupo de poesías anónimas (folios 157r-161r), en las que se detectan correcciones textuales que parecen claramente revisiones de autor (Martí 2002). Como el manuscrito se debe a una única mano, cabría atribuir la autoría de estas piezas al compilador, cuyo origen familiar se debe situar, por razones patrimoniales e históricas, en la familia Pinós: el iniciador de la rama de los marqueses de Santa Maria de Barberà fue Jeroni de Pinós-Santcliment (muerto c. 1584), caballero del orden de San Jaime de la Espada, cuyo hijo, Bernat Galcerán de Pinós Sancliment (m. 1626) recibió del rey el 1599 el señorío y castillo de Santa Maria de Barberà. ${ }^{2}$ Uno de los autores presentes en el manuscrito, y el mejor candidato a ser su compilador, es precisamente el bisabuelo de Jeroni, el caballero Francesc Galcerán de Pinós (c. 1415-1475), quien mantuvo una estrecha relación con el príncipe Carlos de Viana y el dominicano Pero Martines, autores con diversas obras transcritas en nuestro cancionero. ${ }^{3}$

1. La tradición catalana de concursos poéticos tiene su origen en el Consistorio de Tolosa, creado en 1323. Muchos poetas catalanes de los siglos XIV y XV participaron en sus justas, y el prestigio de este certamen impulsó su importación a tierras catalanas sobre todo por el interés especial de la casa real (Riquer 1950). Tenemos testimonios de una organización incipiente en Lérida en 1338 (Gubern 1957), y más tarde de las vicisitudes de su organización en Barcelona. Es posible que en la ciudad condal se estuviera organizando un certamen des de 1393, pero que, por problemas de financiación, no se pusiera en marcha hasta algunos años después, quizás en 1396, año en que se documenta una reclamación del rey a la ciudad de Barcelona para que realice el pago de unas joyas para el premio. En 1398 Joan I se comprometió a pagar los gastos del año, y en 1399 Martí I encargó a Jaume March y a Lluís d’Averçó la organización de un certamen en Barcelona. No ha aflorado información significativa sobre dicha actividad hasta que en 1413 Fernando de Antequera

1 El párrafo final (véase [15]) está incompleto, y además tachado, y se reservaron a continuación cinco folios en blanco para concluir la copia, aunque desgraciadamente la laguna nunca se colmó.

2 El Marquesado de Santa Maria de Barberà fue creado por Felipe V en 1702.

3 A este caballero se atribuye también una traducción, hoy en día perdida, de las Metamorfosis de Ovidio al catalán (Badia 1993: 64), posiblemente desde una versión toscana. Para el cancionero $S^{1}$ / BM1 véanse en general Martí (1997, 1998 y 2002) y Martos (2002). Se puede consultar una descripción exhaustiva del códice, así como diversos datos complementarios, en la base de datos Cançoners DB (http://candb.narpan.net). 
modificó algunos de los aspectos procedimentales. ${ }^{4}$ Un testigo de excepción, Enrique de Villena, describió en su Arte de trovar (1433) la celebración de uno de estos concursos, posiblemente de la época del rey Martí, ya que él mismo sugiere que tras su reinado se estancó la actividad consistorial. ${ }^{5}$

En los cancioneros catalanes de los siglos XIV y XV se copiaron diversas poesías que, ya sea por referencias en su contenido, ya sea porque lo consignan las rúbricas, sabemos que concurrieron a certámenes poéticos, inspirados en las justas tolosanas, que solían conceder una joya como premio. Entre los concursantes podemos citar a poetas como Gilabert de Próixida, Andreu Febrer, Joan Basset, Gabriel Ferrús, Joan Sesavasses, Francí Joan Puculull, Guillem de Masdovelles, Joan Berenguer de Masdovelles, Antoni Vallmanya, Joan Ramon Ferrer, Joan Fogassot, Pere Saguda o Joan Sacoma. ${ }^{6}$

Se conoce muy poco sobre estos concursos, tan bien estudiados en otros ámbitos. ${ }^{7}$ Sin duda algunas noticias publicadas en los últimos años han contribuido a iluminar algunos detalles de estas celebraciones: notablemente los estudios sobre el dominicano barcelonés Felip de Malla (Barcelona, c. 1372-1431), a cargo de Josep Pujol (1994, 1994b y 1996). Malla participó en las ceremonias de estos concursos y la suerte ha ayudado a la conservación de sus intervenciones (Pujol 1996). ${ }^{8}$ Se trata de pequeños sermones pronunciados en el Palacio Real de Barcelona en 1413 «en ocasió d'unes festes de la gaia ciencia, $[y]$ tenen per objecte la definició i l'elogi de la poesia en llengua vulgar» (Pujol 1996: 177). Estos textos tienen importancia, no sólo porque confirman la vigencia de estos concursos y describen aspectos prácticos de su organización, sino también porque son elogiados desde «la talaia culturalment privilegiada d'un mestre en sacra pagina que construeix edificis literaris ambiciosos» (178). Según Pujol, la de Felip de Malla es una voz destacada que contribuye a una estrategia de legitimación de la poesía de tradición trovadoresca, proyectándola en una recuperación

4 Para el Consistori de Barcelona, véase Massó (1932: 309-348), Casas Homs (1956: II, 441-443), Rubió (1979: 23-31 y 1984: I, 197-209); Riquer (1984: II, 565-577), Tavani (1996: 53-81 y 91-109), Rossich (2003: 83-88) y Rossich (2006: 63-71).

5 Sobre el Arte de Trovar de Enrique de Villena, cf. Riquer (1984: II, 68-69), Rubió (1984: 203-204); Cátedra (1981: I, lxxxiv-cxxii).

6 «No ens ha d'estrany ara, doncs, que aquestes celebracions gaudissin de gran prestigi en el món literari català, ni podem menystenir els resultats gramaticals i de versificació que van suscitar des de final del segle XV fins a la vigília del segle XVIII» (Rossich 2003: 88). Para una evaluación de este conjunto de poesías de certamen, véase Sadurní Martí, «La poesia de certamen a la Catalunya dels segles XIV i XV: una valoració històrica i literària», en preparación.

7 Para los concursos tolosanos, véanse Chabanneau (1885), De Gelis (1912) y Jeanroy (1914 y 1941). Para los puys franceses, cf. Gros (1992, 1994 y 2006). Ya para la edad moderna castellana y catalana, véanse también López Estrada (1982), Egido (1978), y Ferrando (1983) y Zaragoza (2016).

8 Para Felip de Malla como autor literario, cf. Riquer 1984: IV, 247-285 y Rubió 1984: 256-269, y ahora Pujol (2015: 370-390). Sin duda su fama como orador tuvo un papel destacado en la conservación de estos sermones 'literarios', incluidos en la compilación homilética malliana del manuscrito 466 de la Biblioteca de Cataluña (Pujol 1998: 234-239).

SCRIPTA, Revista internacional de literatura i cultura medieval i moderna, núm. 10 / desembre 2017 / pp. 1-25 ISSN: 2340 - 4841 doi:10.7203/SCRIPTA.10.11072 
cristiana de la oratoria ciceroniana y de los valores morales de la retórica aristotélica. ${ }^{9}$ Desde esta perspectiva toma especial sentido la caracterización de los discursos de entrega de premios que Villena evocaba en su Arte de trovar: uno de ellos a cargo de un maestro en teología, con elogio de la poesía vulgar y una glosa del tema, y otro a cargo del marqués, con glosa de las poesías presentadas y elogio de las premiadas (Sánchez Cantón 1993: 58-60).

2. El discurso que nos ocupa, redactado en catalán pero con abundantísimos pasajes en latín, está encabezado por una rúbrica con informaciones de gran interés: Oracio facta per materia de complanctu amoris, anno Domini mcccctrisesimo octavo, in Sancto Justo Barchinone. El concurso tuvo lugar, pues, en Barcelona, en la iglesia de Sant Just, en el año de 1438 y el tema fue la lamentación de Amor. Desgraciadamente, ni la rúbrica ni el contenido señalan al posible autor del discurso. Algunas características del texto y su transcripción en el cancionero podrían ser pistas útiles para formar hipótesis atributivas, siempre con gran prudencia, hasta que puedan verificarse con otros datos. Por una parte, el estado claramente incompleto podría llevar a pensar que se trata de un borrador, y por la otra la proximidad espacial con las aludidas poesías con variantes redaccionales, podrían invitar a considerar una atribución a Francesc Galceran de Pinós. Sin embargo, conviene tener en cuenta que este caballero nació hacia 1415 y que, por lo tanto, en 1438 tendría unos veintitrés años. La cultura y, sobre todo, el prestigio que conlleva la redacción de un discurso de estas características parecen desaconsejar esta atribución (aunque evidentemente no la invalidan). Tengamos en cuenta, además, que el compilador de $S^{1}$ realizó esta transcripción, fragmentaria y con defectos de copia, hacia 1470, es decir treinta años después del concurso en cuestión. Por otra parte, la estructura y el estilo de la sentencia recuerdan poderosamente a los sermones-discurso de Felip de Malla. Si bien el dominicano murió en 1431, tanto el aparato erudito de alusiones como el engarce de discurso vulgar y latino invitan a pensar en un perfil parecido, quizás también formado en el ámbito eclesiástico. Con estas posibles vías de investigación planteadas, por el momento la cuestión de la autoría deberá dejarse en suspenso. ${ }^{10}$

Tras la rúbrica, un breve exordio en latín alude a los destinatarios (los «uiri percelebres»y «presentes conscripti» reunidos «isto in consistorio») y manifiesta que la sentencia está redactada en catalán («uulgari sermone maternoque eloquio») y organizada como un diálogo entre el autor y Amor («admodum dialogi inter nos et ipsum Amorem interrogando et respondendo»). También nos confirma que el tema del concurso era el «de Amoris complanctu». En su estado actual, el discurso presenta dos secciones: un diálogo inicial entre Amor y el anónimo autor (que aparece siempre inscrito como «уо») viene completado por una segunda parte, más breve en el estado fragmentario actual, donde se glosa sucintamente lo que parece ser la terna de poesías finalistas del concurso.

9 Pujol (1994: 186-196) argumenta extensamente la filiación de esta nueva manera de enfrentarse a la poesía. Para una interpretación en una línea parecida, ya para la última generación de trovadores, véase Cabré/Martí/Navàs (2009), y más recientemente Cabré/Navàs (2014).

10 Naturalmente, por el contexto del propio cancionero $S^{1}$, un candidato posible sería el dominicano Pero Martines (c. 1400-1463), circunstancia que dejamos aquí inscrita solo como hipótesis. Para Martines, véase ahora Martí (2015). 
La organización del discurso, pues, parece adaptarse al ritual de las ceremonias de consistorio tal y como las describió Villena. Sin embargo, y a diferencia de los textos de Villena y Malla, una de las características más excepcionales del texto copiado en $S^{1}$, como veremos, es que se trata de una de las únicas ocasiones en la Edad Media hispánica en que se ha conservado no sólo el discurso retórico de concesión, sino también la glosa de algunas poesías.

En el diálogo, con visos de teatralización, Amor responde a cuatro preguntas: a) ¿Quién sois?; b) ¿De qué vivís?; c) ¿Qué hacéis y para qué servís?; y d) ¿Por qué os marcháis y morís? A pesar del estado de la redacción, la estructura reconocible obedece al siguiente esquema:

1 ¿Quién sois y de dónde venís?

Soy vida. Argumento etimológico. El amor convierte a los amantes en un solo elemento (ejemplos bíblicos y mitológicos). Vengo de complacencia (conformidad de calidades y virtudes)

2 ¿De qué vivís y cómo os mantenéis?

Me mantengo y vivo de comidas placenteras.

3 ¿Que hacéis y para qué servís?

Sé alimentar, proveer, servir y argumentar.

4 ¿Por qué partís?

Parto al exilio por desconocimiento (desconeixença)

Aunque las partes del diálogo se pueden aislar con facilidad, su presentación en la literalidad del testimonio es compleja, y a veces incluso confusa. El problema principal reside en la manera de insertar en el texto catalán los locilatinos, ya que presenta fronteras inciertas, con grandes dificultades para la lectura.

Otro aspecto de este discurso que merece ser destacado es precisamente un cierto aire de diálogo teatralizado entre Amor y el autor Veamos este aspecto:

[1] Com, primerament, yo interrogaré Amor, e dir-li é: «Digau, Amor: e què sou vós ni d'on procehiu?» E aprés diré: «Digau, Amor: e de què us manteniu vós, ne de què viviu?» $\mathrm{E}$ aprés demanar-li he: «Digau, Amor: e què sabeu fer vós, ne de què serviu?» E més saber volré, dient: «Amor: per què us hic partiu vós, ne de quin mal moriu?»

[2] Quant al primer, respon Amor, e diu axí: «Vós demanau yo què són? Así us responch que yo són vida». Dich yo: «Amor, com ho provau?» Respon Amor: «Per lo meu nom». Dich yo: «Amor, e com?»

«Axí — respon Amor-: Amor vol dir tant com 'sens mort': ab a —quae est 'sine' — et mor — quasi 'sine morte'. Donchs — diu Amor_-, pus són sens mort, vida són yo. Hon diu per mi l'anemorat (sent Agustí, in libro De utilitate credendi): "Quid est amor, nisi nita duo copulantis, uel copulare appetens, amantem videlicet, et quod amatur?»); tant que Amor lo més que pot transforma l'amant en la cose que ama, per manera que Amor fa l'amich o l'amat en lo amant altre si matex e per amor una cosa (VIII Ethicorum), axí com fou de Theseo e Pirotheo, qui suplicaren los déus que de lurs dos cossos fes hun sol cos; et Ouidius (4 Methamorphoseos) de Sàlmata, que tant amà Elmofoditum, que per lo semblant pregà los déus que de ells dos fos fet un sol, «quae et factum est, et habuit utrunque sexum, unde exinde tales hermofroditi dicti sunts. 
Como podemos ver, al iniciar su primera respuesta Amor recurre a un aparato erudito, procedimiento que salpica continuamente su discurso y también las glosas a los poemas. En su argumentación el anónimo recurre indistintamente a fuentes bíblicas y a autoridades clásicas y patrísticas (Aristóteles, Séneca, Ovidio, Cicerón, san Agustín, san Ambrosio, san Gregorio, Casiodoro, san Isidoro, Boecio y san Bernardo).

En los argumentos desgranados a lo largo del diálogo, Amor se define a sí mismo como vida, y manifiesta que por su virtud consigue igualar a los amantes y los convierte en un solo ser (con ejemplos de Teseo y Piroteo, Salmacis y Hermafrodito, Siquén y Dina, Jonatás y David, etc.) Afirma que procede de «complacença», y que vive y sirve a la «dolça benevolença», al tiempo que huye y parte a causa de gran «desconeixença». La complacencia, a su vez, procede de la similitud, y muy especialmente de la concordancia de calidades y virtudes. Amor vive de tres alimentos placenteros, a saber: la adecuación de los ánimos, la revelación de los secretos y la comunicación de los bienes. Al detallar sus tres sustentos, asevera en primer lugar que iguala las almas de los amantes, de manera que no hay dominio de uno sobre otro, y por la que se debe amar tanto como ser amado. En segundo lugar, vive de la comunicación de los secretos, por lo cual se debe confiar en los amantes. Y en tercer lugar, se alimenta de la comunión de bienes y de su opuesto, la comunión de los malos momentos o de fracasos. Amor define su arte y oficio en el apartado siguiente afirmando que consiste en nutrir y proveer, servir y argüir. Es a causa de estos oficios, sobre todo del de reprender a los falsos amantes, por lo que Amor acaba siendo menospreciado y finalmente tiene que abandonar el mundo.

A continuación, se reseñan tres poesías que compitieron por el mismo premio, sin duda la terna finalista. La enumeración reza: «Lo primer és qui ‘s ret falló nostre senyor, l’amorós déu. Lo segon és En Castelló, home d'onor, qui 's mossèn Barthomeu. Lo tercer és d'est papelló alarredor tothom arreu». De las tres poesías sólo se glosan dos, puesto que de la de Bartomeu Castelló se afirma: el «segon amorós qui 's complany de amor és mossèn Castelló, lo quall, pus ha edat perfeta e complida, parlarà ell matex e farà sa complanta», circunstancia que parece permitirnos excluirle a su vez como autor de esta Oratio. ${ }^{11}$

El comentario de la primera poesía se inicia con unos versos (reproducidos de manera imperfecta y a modo de prosa en $S^{\dagger}$ ) que son un parlamento de Amor en primera persona. Tras ello se indican las razones por las que hay que se debe amar a Dios (Padre, Hijo y Espíritu Santo), especialmente por el amor que Él tiene a los hombres (Encarnación). Se debe amar a Dios dulcemente, prudentemente y con fortaleza y por encima de todas las cosas, ya que es el bien supremo y el principio y fin de todo. ¡Qué razón tiene Amor al quejarse de cómo le menosprecian los hombres! ¡Amamos al mundo y a sus locuras, y no a nuestro Creador! Dejar a Dios por una criatura es la mayor perversidad del hombre. Y además, amar a Dios por lo que se espera obtener de él es muy reprobable, y por ello Amor se queja ante los hombres.

11 Podría establecerse un paralelo con el caso del jurista Joan Ramon Ferrer, de quien se ha conservado un sirventés con una extensa glosa, escrita por él mismo, en el cancionero Vega Aguiló (Cabré 2002 y 2002a). 
La glosa de la tercera poesía afirma que todos quieren jugar con ventaja, o fraudulentamente, en el amor. Pero eso no es amor sino engaño, porque se basa en la intención de conseguir el amor sin amar. No se trata de amar para obtener un bien honesto, sino el deleite y el interés, como les ocurre a los niños. Cuando se desea aquello que la persona a quien se ama no posee, el único desenlace posible es la queja: es un amor falso y engañoso, y por ello conduce a querellas. Hay que amar de corazón y sin esperar nada a cambio.

3. Aunque la sentencia de $S^{1}$ no se haya editado ni estudiado hasta ahora, el certamen de Sant Just es conocido también por otra fuente: el Cancionero de los Masdovelles (Barcelona, Biblioteca de Catalunya, ms. 11; sigla $M$ ), códice autógrafo de Joan Berenguer de Masdovelles, que contiene una masiva compilación de sus propias poesías y de las de su tío Guillem de Masdovelles, entre otros pocos poetas. A menudo las poesías van precedidas de rúbricas explicativas, con informaciones de tipo muy variado, relacionadas con aspectos retóricos y métricos, o con la fecha y el motivo de la composición. Entre estas rúbricas nos interesa destacar la que reza: En lo mes de juyn, any мсСССXXXVIII, en la ciutat de Barchalona, donà mossèn Berthomeu Castelló una joha a qui mils se complenyaria de mor, un se donaren moltes hobre [s], entre les quals n'i donà en Guillem de Masdovelles la següent en deffensió del deu de mor e contra los trobadors qui s compleynien (n. 50; f. 31 ${ }^{\mathrm{r}}$, rubr xxxiiiij $\left.{ }^{\mathrm{r}}\right)^{12}$ Es decir que en junio de 1438 el caballero Bartomeu Castelló concedió una joya a quien se lamentara de Amor en un concurso, con mucha participación, que tuvo lugar en la iglesia de Sant Just de Barcelona. La poesía que acompaña a esta rúbrica («Del cruzel crim de lleza magestat» RAO 101.1) pertenece a uno de los concursantes, Guillem de Masdovelles, quien defendió a Amor contra los poetas que concursaron vilipendiándole. Estamos a todas luces ante el mismo concurso de la sentencia que reproduce el Cancionero del Marqués de Barberà (el tema era allí «per materia de complanctu Amoris» y en este segundo testimonio «a qui mils se complenyaria de mor»), aunque allí no se indicara ni el mes ni el convocante, y aquí se sitúe genéricamente en Barcelona, pero no la iglesia de Sant Just. No acaba así la información preciosa que aporta el cancionero $M$, porque en la rúbrica de la poesía sucesiva se puede leer: Cansso de rims unisonans feta per Johan Berenguer de Masdouell[e]s, la qual féu per la raó desús dita, he tirà la joha (n. 51; f. 31 ', rubr Xxxinj'). Así pues, en este concurso de Sant Just participaron tío y sobrino, y además Joan Berenguer ganó la joya con la poesía «De vos, Amor, no pusch ges null bé dir» (RAO 103.38).

Por otra parte, salvo error, no se han conservado poesías a nombre de Bartomeu Castelló en ninguno de los testimonios medievales. Sin embargo, Vicenç Beltran (2006) publicó una regesta de los contenidos de un cancionero gerundense del siglo XV, hoy perdido, copiada en un documento de finales del siglo XVIII. Nuestro autor aparece allí mencionado entre diversos poetas coetáneos. ${ }^{13}$

12 Sobre este cancionero véase el estudio completo de Beltran (2006), al que sigo en la transcripción de las rúbricas. Para más datos complementarios, véase la ficha correspondiente en la base de datos Cançoners DB (http:// candb.narpan.net).

13 Sobre este cancionero Beltran (2006: 116) indica que «al segle XVIII, al col legi dels jesuites de Girona, es conservaven dos manuscrits, probablement amb un disseny unitari, que es perderen com a conseqüència de l'expulsió de l'orde i el desori que es produí amb els llibres de la seva biblioteca. L'orientació d'aquests reculls havia

SCRIPTA, Revista internacional de literatura i cultura medieval i moderna, núm. 10 / desembre 2017 / pp. 1-25 ISSN: 2340 - 4841 doi:10.7203/SCRIPTA.10.11072 
Beltrán propone identificar a Bartomeu Castelló con un personaje ilustre de la Barcelona de inicios del siglo XV: fue veguer de Barcelona (1422), participó con veinticinco miembros más del patriciado urbano en el cortejo que condujo los restos de la reina Violante (1431), en la conmemoración del funeral de la reina de Portugal (1455) y en diversas celebraciones ciudadanas, como en la fiesta de Corpus de 1455 y en una conmemoración de la armada real de 1457. En diversos documentos fechados entre 1422 y 1464 aparece como firmante y, finalmente, sabemos que embarcó junto a Guillem Oliver y Baltasar Romeu hacia Tierra Santa en $1464 .{ }^{14}$ Sucintamente, pues, se dibuja el perfil de un hombre eminente de la ciudad de Barcelona, seguramente con formación jurídica, que ostentaba cargos públicos y que se codeaba con ciudadanos ilustres.

Los datos sobre la participación de los Masdovelles y la implicación de Castelló parecen encajar perfectamente con la información que proporciona nuestro discurso. Lo sorprendente de la sentencia poética reportada por $S^{1}$ es que en ella Bartomeu Castelló no sólo no es señalado como convocante, como indica la rúbrica de $M$, sino que parece que sea presentado como concursante. ¿Podía participar el convocante de un concurso en la misma liza? ¿Y si la respuesta es negativa, cómo hay que interpretar esta contradicción? Por el momento son interrogantes a la espera de una aclaración satisfactoria. En todo caso, Castelló se une a la lista de diversos personajes que a lo largo del siglo XV promocionaron concursos poéticos con temas particulares, dotados con una joya preciosa como galardón: tenemos noticias de las justas patrocinadas por Francí Bussot «a qui millor destruieixi Crueltað); por Antoni Çaplana con motivo de la caída de Constantinopla; por Montserrat Torres sobre santa Magdalena; por Martí Bellit sobre Desconeixença, etc. ${ }^{15}$ Así pues Castelló se adapta perfectamente a los usos de su tiempo, y su perfil profesional le acerca incluso a algunos de los autores que a lo largo de los siglos XIV y XV participan en el Consistorio poético de Barcelona o glosan o emiten sentencias poéticas relacionadas con él, como el caso de Joan Fogassot (Cabré 2002).

Por lo que respecta a la segunda sección del texto, donde se citan y se glosan las poesías premiadas, también ahí podemos aportar elementos de interpretación a partir del discurso que se publica, pero no alcanzamos a disipar todas las dudas a causa de la fragmentariedad y la falta de rigor de la copia. Como se ha comentado, la glosa del primer poema se construye sobre la «desconexença» de los hombres hacia el dios de Amor (siguiendo un paralelismo crístico). Tanto los versos que podemos reconstruir en el manuscrito, donde Amor expresa sus quejas en primera persona, como los temas

de ser marcadament didàctica: feia una selecció de preceptives lingüístiques i literàries de l'escola occitana i les seves derivacions baixmedievals, però contenia a més un recull de poesia». Entre los poetas identificados se encuentran los cuatrocentistas Antoni Saplana y Bartomeu Castelló. El cancionero también reproducía obras de Giraut de Bornelh, Bertran de Born, Peire Catala, Ramon At de Montaut, Joan Flamench, Guilhem Alaman y los todavía no identificados Nicolau Canyelles, Bernat Palmarola, Lleonard de Vallseca, Gabriel d'Arques y Miquel Llopis (109-113).

14 Para todos estos datos, cf. Beltran (2006: 112). Francisco Javier Rodríguez Risquete me ha indicado amablemente que un Bartomeu Castelló firma, a 26 de mayo de 1422, la copia de una Definición y remisión (o cierre) de cuentas (pendientes) firmada por Grayda y Elionor de Torrelles a favor de Pere Ragassol, prebere y canonje de la santa iglesia de Barcelona, de 3 de mayo de 1421.

15 Cf. Ferrando (1983: 29-124) y Rossich (2003: 86-88).

SCRIPTA, Revista internacional de literatura i cultura medieval i moderna, núm. 10 / desembre 2017 / pp. 1-25 ISSN: 2340 - 4841 doi:10.7203/SCRIPTA.10.11072 
apuntados por la glosa del texto ganador, coinciden perfectamente con la poesía de Guillem de Masdovelles «Del cruzel crim de lleza magestat» (RAO 101.1), que da la palabra a Amor para que presente su queja en primera persona ante los amantes del mundo por su deslealtad:

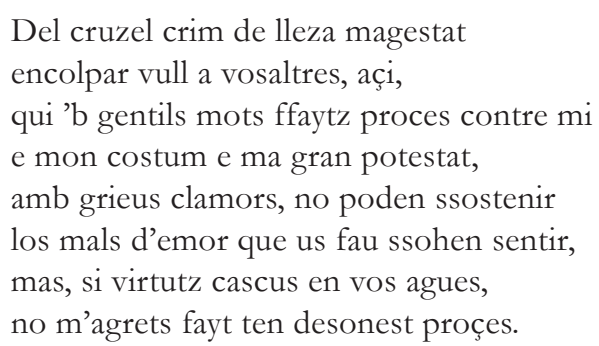

Yeu suy le dieus d'emor, quez ay conques caixs tot lo mon ab los colps del mieu dart, e ges nulls homs no 'n ha ten ssoptil art, q'ab sol un colp no l'aya llieu ssotsmes, pero 1 gentil quez han cor virtuos, cant son neffrat d'eytal colp amoros son plus valen, e no 's volon clamar del mal qui ls ffay en pretz d'onor montar. (vv. 1-16; Aramon 1938, p. 59. Citamos siempre de RialC)

En el poema de Guillem, Amor insiste en la ingratitud de los amantes que sólo esperan su beneficio y da una lista de amantes que nunca se quejaron a pesar de sus penas amorosas:

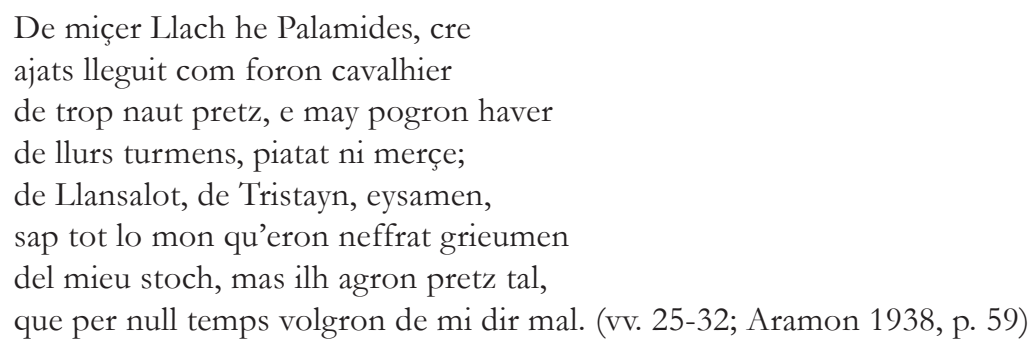

La coincidencia temática es absoluta, y ambos textos se asemejan también en la forma de soliloquio de Amor (aunque el concepto de amor reflejado difiera). Sin embargo, no hay correspondencia textual entre el texto de Masdovelles y los versos reproducidos tras el epígrafe «Diu lo primer». Cabe preguntarse si el poema de Guillem de Masdovelles concursó pero no obtuvo premio (al fin y al cabo la rúbrica no especifica que fuera premiado), cosa que explicaría la coincidencia temática, o si los versos copiados de manera tan poco rigurosa en el discurso son una glosa rimada por parte del autor del discurso a la composición de Masdovelles. En el primer caso, el lamento de Amor de Masdovelles fue derrotado por un poema estructuralmente parecido, que en algún pasaje reflexionaba sobre la caridad como atributo divino, dando un giro al tema profano propuesto. En el segundo, fue el autor anónimo quien realizó una glosa a lo divino en forma versificada, que luego equipara con ejemplos profanos al aportar las autoridades latinas. 
La otra poesía, «De vos, Amor, no pusch ges null bé dir» (RAO 103.38), escrita por Joan Berenguer de Masdovelles y premiada en el concurso de Sant Just según la rúbrica del cancionero, guarda asimismo estrecha relación temática con la glosa que se halla copiada en nuestro manuscrito. El poeta se enfrenta personalmente a Amor, afirmando no haber obtenido ningún bien de él:

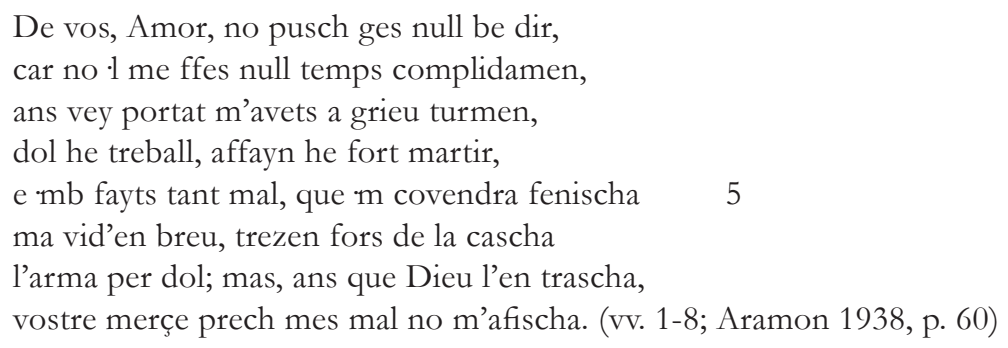

La poesía acaba con un doble envoi: el primero a la dama, y el segundo a los entendidos que deben valorar su poesía en el concurso: «A cascu prech, senyors, que m corragischa / l'obra present, si y trobats ges de frascha, / e ssi falç cars n'altre viçi l'enfrascha, / rezets lo 'n prim, per qu'ieu mils la lagischa» (vv. 45-48). Si en el caso anterior, de ser cierta la atribución a Guillem de Masdovelles, la glosa exploraría el paralelo con la caridad divina, en esta glosa el anónimo daría un giro moral al poema del sobrino: equipara las circunstancias del amor, y el ánimo con que las afrontan los malos amantes, a de la actitud ante «armes, e plets e jochs», y censura a quien se queja de amor sin razón.

4. Recapitulando, estamos ante un texto peculiar que transcribe parcial y rápidamente el discurso de concesión de premios de un concurso poético sobre el lamento de Amor patrocinado por Bartomeu Castelló en la iglesia de Sant Just de Barcelona en 1438. El texto combina un discurso inicial sobre la naturaleza del Amor con una glosa de la terna finalista. Siguiendo los usos que se documentan, por ejemplo, en Felip de Malla, a lo largo de la pieza se alternan secciones en lengua catalana, a veces en un formato que parece un diálogo teatralizado, con un aparato erudito de refuerzo que acumula citas de autoridades en lengua latina. El caso que nos ocupa es uno de los pocos en la Edad Media hispánica donde poseemos el discurso de concesión y las piezas que concurrieron, circunstancia que ayuda a dibujar de manera más precisa cómo debían ser las ceremonias de entrega de premios en las justas poéticas tardomedievales. Sobre la autoría del discurso conviene ser cauto, pues que todas las posibles hipótesis se deducen con pocas seguridades y de manera indirecta. En cambio, como hemos sugerido, nos parece claro que el perfil del autor debería asemejarse al de un clérigo de formación e intereses parecidos a los de Felip de Malla. En todo caso, esperamos haber mostrado el interés que presenta esta Oratio del Cancionero de Barberà, tanto por sí misma como para la interpretación de poesías conocidas. Y también esperamos haber conseguido demostrar que vale la pena emprender un estudio más pormenorizado de la tradición de concursos poéticos de los siglos XIV y XV en la Corona de Aragón, un tema que puede depararnos todavía bastantes sorpresas. 
Sadurní Martí. La sentencia del certamen poético de Sant Just (1438): edición y estudio preliminar

\section{Bibliografia}

Aramon i Serra, R. (1938) Cançoner dels Masdovelles. Cançoners catalans de la Biblioteca de Catalunya, 1, Barcelona, Institut d'Estudis Catalans.

Badia, L. (1993) «Per la presència d'Ovidi a l'Edat Mitjana catalana, amb notes sobre les traduccions de les Heroides i de les Metamorfosis al vulgar ", en Tradició i modernitat als segles XIV i XV. Estudis de cultura literària i lesctures d'Ausiàs March, València-Barcelona, Institut Universitari de Filologia Valenciana-Publicacions de l'Abadia de Montserrat, pp. 39-71.

Balasch, M. ed. (1981) Felip de Malla, Memorial del pecador remut: Manuscrit de Barcelona, Barcelona, Barcino, vol. 1.

Beltran, V. (2006) «El cançoner perdut de Girona: els Mayans i l'occitanisme il lustrat», Trobadors a la peninsula ibérica: Homenatge al Dr. Martí de Riquer, ed. V. Beltran, Meritxell Simó, Elena Roig, Barcelona, PAM, pp. 91-120. (2006a) El Cançoner de Joan Berenguer de Masdovelles, Barcelona, PAM.

Cabré, M. (2002) «Jutges, processos i sentències en la lírica del XV: Joan Ramon Ferrer, mantenidor del gai saber (1475)», Estudi General, 22, pp. 409-20.

(2002a) «El saber de Joan Ramon Ferrer», Literatura i cultura a la Corona d'Aragó, ed. L. Badia, M. Cabré, S. Martí, Barcelona: Curial/PAM, pp. 409-20.

Cabré, M / Navàs, M. (2014) "“Que 1 rey franses nos ha dezeretatz": la poètica occitana després de Muret», en 800 anys després de Muret. Els trobadors i les relacions catalanooccitanes, ed. V. Beltran, T. Martínez, I. Capdevila, Barcelona, Universitat de Barcelona, pp. 101-122.

Cabré, M / Martí, S. / Navàs, M. (2009) «Geografia i història de la poesia occitanocatalana del segle XIV», Traslatar i transferir. La transmissió dels textos i el saber (1200-1500), ed. A. Alberni, L. Badia i L. Cabré, Santa Coloma de Queralt, Obrador Edèndum/Publicacions URV, pp. 349-376.

CANÇONERS DB: Canconers DB http:/ / canbd.narpan.net.

Casas-Homs, J. M. (1956) «Torcimany» de Luis de Averçó. Tratado gramatical y diccionario de rimas. Siglos XIV-XV, Barcelona, CSIC, 1956, 2 vols.

Cátedra, P. M. (1981) Sobre la vida y la obra de Enrique de Villena. Tesis doctoral. Barcelona: Universidad Autónoma, 1981. 9 vols.

Chabaneau, C. (1885). «Origine et établissement de l'Académie des Jeux Floraux de Toulouse», Dom Cl. Devic \& Dom J. Vaissete, Histoire générale de Languedoc avec des notes et les pièces justificatives, Tolosa, Privat, X, 177-208.

Egido, A. (1978) «Los modelos en las justas poéticas aragonesas del siglo XVII», Revista de Filología Española, 60.1/4, 159-171.

Gélis, L. F. De (1912). Histoire critique des Jeux Floraux depuis leur origine jusqu'à leur transformation en Académie (1323-1694), Tolosa, Privat.

SCRIPTA, Revista internacional de literatura i cultura medieval i moderna, núm. 10 / desembre 2017 / pp. 1-25 ISSN: 2340 - 4841 doi:10.7203/SCRIPTA.10.11072 
Gros, G. (1992) Le poète, la vierge et le prince du Puy. Étude sur les Puys marials de la France du Nord du XIVe siècle à la Renaissance, París: Klincksieck.

(1994) Le poète, la vierge et le prince. Étude sur la poésie mariale en milieu du cour aux XIVe et XVe siècles, Saint-Etienne: Publications de l'Université de Saint-Etienne.

(2006) «Histoire littéraire et Puy poétique: la poésie mariale de concours au Moyen Âge», Travaux de littérature, 19, pp. 39-55.

Ferrando Francés, A. (1983) Els certàmens poètics valencians dels segles XIV al XIX, València, IAM.

Gubern, R. (1957) «Els primers jocs florals a Catalunya: Lleida, 31 de maig de 1338», Bulletin of Hispanic Studies, 34, pp. 95-96.

Jeanroy, A. (1914) Les Joies du Gai Savoir. Recueil de poésies couronnées par le Consistoire de la Gaie Sciencie (1324-1484), Tolosa, Privat.

(1941) «La poésie provençale dans le sud-ouest de la France et en Catalogne du début au milieu du XIVe siècle», a Histoire littéraire de la France, París, Imprimerie Nationale, XXXVIII.1, 139-233.

López Estrada, F. (1982) «Fiestas y literatura en los Siglos de Oro : la Edad Media como asunto 'festivo' (el caso del Quijote)», Bulletin Hispanique, 84.3-4, pp. 291-327.

Martí, S. (1997) «El Cançoner del marquès de Barberà ( $\left.S^{1}-B M 1\right)$. Descripció codicológica», Boletín Bibliográfico de la Asociación Hispánica de la Literatura Medieval, 11, pp. 463-502.

(1998) «Fonts i problemes del Cançoner del marquès de Barberà $\left(S^{1}-B M 1\right) »$, Atti del XIX Congresso internazionale di linguistica e filologia romanza (1995), Palermo, Centro di Studi Filologici e Linguistici Siciliani, IV, pp. 459-485

(2002) «Escolios sobre impaginación y variantes redaccionales en Montserrat 992», dins Proceedings of the Twelfth Colloquium of the Medieval Hispanic Research Seminar of the Queen Mary and Westfield College (1-2 july 1999), London, Department of Hispanic Studies, Queen Mary, University of London, pp. 67-76.

(2015) «Pero Martines», en Història de la literatura catalana. Literatura medieval, III: segle XV, dir. Lola Badia, Barcelona, Enciclopèdia Catalana/Barcino/Ajuntament de Barcelona, pp. 367-370.

Martos, J. L. (2002) «Los espacios en blanco y la estructura del Cançoner del Marquès de Barberà», dins Proceedings of the Twelfth Colloquium of the Medieval Hispanic Research Seminar of the Queen Mary and Westfield College (1-2 july 1999), London, Department of Hispanic Studies, Queen Mary, University of London, pp. 57-65.

Massó Torrents, J. (1932). Repertori de l'antiga literatura catalana. La poesia, I, Barcelona, Alpha.

Pujol, J. (1994) "Gaya vel gandiosa, et alio nomine inveniendi sciencia: les idees sobre la poesia en llengua vulgar als segles XIV i XV”, Intel Vectuals i escriptors a la baixa Edat Mitjana, ed. Lola Badia i Albert Soler, Barcelona, Curial-PAM, pp. 69-94. 
Sadurní Martí. La sentencia del certamen poético de Sant Just (1438): edición y estudio preliminar

(1994b) "Els trobadors estudiosos segons Felip de Malla", La cultura catalana tra l'umanesimo e il barocco. Atti del V Convegno dell'Associazione Italiana di Studi Catalani, ed. Carlos Romero i Rossend Arqués, Pàdua, Programma, pp. 191-208.

(1996) "Psallite sapienter: la gaia ciència en els sermons de Felip de Malla de 1413. Estudi i edició”, Cultura neolatina, 56.1-2, pp. 177-250.

Renedo, X. (1990-91) «Una imatge de la memòria entre les Moralitates de Robert Holcot i el Dotzè de Francesc Eiximenis», Annals de l'Institut d'Estudis Gironins, 31, pp. 53-61.

RiALC: Repertorio Informatizzato dell'Antica Letteratura Catalana http:/ / www.rialc.unina.it

Riquer, M. de (1950) «Contribución al estudio de los poetas catalanes que concurrieron a las justas de Tolosa», Boletin de la Sociedad Castellonense de Cultura, 294-99 i 305-308.

(1984-85) Història de la Literatura Catalana. Part Antiga, Barcelona, Ariel, 4 vols.

Rossich, A. (2003) «Els certàmens literaris a Barcelona, segles XIV-XVIII», dins Barcelona Quaderns d'Història 9: La Barcelona ideal i la Barcelona real en la cultura literària de l'Edat Moderna, ed. Eulàlia Duran i Eulàlia Miralles Jori, Barcelona, Ajuntament de Barcelona, pp. 83-108.

(2006) «Els certàmens: de la gaia ciencia als jocs florals», dins Actes del Tretzè Col loqui Internacional de Llengua i Literatura Catalanes, ed. S. Martí et al., Barcelona, PAM, Abadia de Montserrat, vol. I, pp. 63-90.

Rubió i Balaguer, J. (1979) De l'Edat mitjana al Renaixement, Barcelona, Teide.

(1984) Història de la Literatura Catalana, Barcelona, Departament de Cultura de la Generalitat de Catalunya i PAM, vol. I.

Sánchez Cantón, F. J. (1993) Don Enrique de Villena, «Arte de trovan», Madrid, Visor.

Tavani, Giuseppe (1996). Per una història de la cultura catalana medieval, Barcelona, Curial.

Zaragoza, V. (2016) «En vers vull desafiar...». La poesia femenina a l'àmbit català (segles XVI-XVIII). Edició crítica", tesi doctoral inèdita, Universitat de Girona.

SCRIPTA, Revista internacional de literatura i cultura medieval i moderna, núm. 10 / desembre 2017 / pp. 1-25 ISSN: 2340 - 4841 doi:10.7203/SCRIPTA.10.11072 


\section{APÉNDICE \\ EDICIÓN DEL DISCURSO DE SANT JUST ${ }^{16}$}

$[0]$

\section{$[\mathrm{R}]$ Oracio $^{17}$ facta pro $^{18}$ materia de complanctu Amoris. Anno Domini $\cdot \mathbf{M}^{\cdot} \mathrm{CCCC}^{\mathrm{o}}$ trisesimo octavo, in Sancto Iusto Barchinone}

[0] Tam espectabili quam preclaro isto in consistorio, ${ }^{19}$ prespicaci ingenio, ${ }^{20}$ quin yme et uenustatis ${ }^{21}$ magne, o uiri percelebres set et multe reuerencie domini!, atque patres conscripti, quos, sacra uestalis Minerua dinersarum fronesum per undique difuse circunfluit, prolocuturus ego ipse unlgari sermone maternoque eloquio amplioris acceptationis gratia aut comunionis, uti iusum est meis precetoribus ymo et dominis quam plurimum recolendis, hanc ob causam materiam circa subiectam de ${ }^{22}$ Amoris complanctu ad modum dialogi cuiusdam inter nos et ipsum Amorem, interrogando et respondendo; Amoris dinini suffragante adminiculo nostrum expandatur exordium. ${ }^{23}$

[1] Com, primerament, yo interrogaré Amor, e dir-li é: «Digau, Amor: e què sou vós ni d'on procehiu?» $\mathrm{E}$ aprés diré: «Digau, Amor: e de què us manteniu vós, ne de què viviu?» $\mathrm{E}$ aprés

16 Para la edición de este discurso se han seguido los criterios habituales para los textos catalanes medievales. Se respeta la grafía del manuscrito y sólo se regulariza $i / j$ y $u / v$. Se resuelven las abreviaturas sin indicación expresa y se separan y acentúan las palabras de acuerdo con la norma actual. Para el caso especial de palabras aglutinadas sin representación moderna, se resuelven con punto medio. En el caso del latín, se regulariza de acuerdo a la práctica habitual en la edición de textos clásicos y medievales. Se consignan en el aparato crítico todas las lecciones enmendadas así como los accidentes de copia.

17 Una corrección ilegible afecta a una palabra eliminada, corregida por un Oracio añadido en la interlínea.

18 Corrección ilegible que afecta a cuatro palabras, eliminadas y corregidas por una anotación superior pro redundante, pues ya se encuentra más tarde en la rúbrica.

19 consistorio $\{\mathrm{i}\}$ del.

20 jngenjo $\{\mathrm{s}\}$ del.

$21 \mathrm{ue}\{\mathrm{tu}>\mathrm{nu}\}$ statis del. et interl.

22 de $\{$ ano $\}$ del.

23 Discurso sobre el tema del planto del Amor. En el año del Señor de 1438, en Sant Just de Barcelona. En este consistorio tan admirable como munífico, de agudo ingenio y gran belleza, oh prohombres de renombre y también señores muy reverendos y senado eximio, a quienes la divina vestal Minerva rodea copiosamente y por todos lados con flores diversas, me propongo hablar yo mismo, en lengua vulgar y habla materna, para una aceptación o comunión mayores, como fue ordenado a mis maestros o señores muy venerables, en esta ocasión, sobre el tema prefijado del planto del Amor, en forma de un diálogo entre yo y el Amor, preguntando y respondiendo; con la ayuda valedora del Amor divino se despliegue ahora nuestro exordio. 
demanar-li he: «Digau, Amor: e què sabeu fer vós, ne de ${ }^{24}$ què serviu?» $\mathrm{E}$ més saber volré, dient: «Amor: per què us hic partiu vós, ne de quin ${ }^{25}$ mal moriu?»

[2] Quant al primer, respon Amor, e diu axí: «Vós demanau yo què són? Así us responch que yo són vida». Dich yo: «Amor, com ho provau?» Respon Amor: «Per lo meu nom». Dich yo: «Amor, e com?»

«Axí — respon Amor-: Amor vol dir tant com 'sens mort': ab a — quae est 'sine - et mor - quasi 'sine morte'. Donchs — diu Amor-, pus són sens mort, vida són yo. Hon diu per mi l'anemorat (sent Agustí, in libro De uti[146r] litate credendi): "Quid est amor, nisi nita duo copulantis, ${ }^{26}$ uel copulare ${ }^{27}$ appetens, amantem videlicet, et quod amatur?»); ${ }^{28}$ tant que Amor lo més que pot transforma l'amant en la cose que ama, per manera que Amor fa l'amich o l'amat en lo amant altre si matex e, per amor, una cosa (VIII Ethicorum), ${ }^{29}$ axí com fou de Theseo ${ }^{30}$ e Pirotheo, qui suplicaren los déus que de lurs dos cossos fes hun sol cos; ${ }^{31}$ et Ouidius (4 Methamorphoseos) de Sàlmata, que tant amà Elmofoditum, que per lo semblant pregà los déus que de ells dos fos fet un sol, «quae et factum est, et habuit utrunque sexum, unde exinde tales hermofroditi dicti ${ }^{32}$ sunts. ${ }^{33}$

[3] Per què dich yo: «O, donchs, Amor! Tan gran és vostre força! E car vós ${ }^{34}$ feu sert $^{35}$ so que no pot natura, e ço a què natura no basta vós trespassau, e ço ${ }^{36}$ que natura disjuny vós copulau, uniu ${ }^{37}$

$24\{\mathrm{a}>\mathrm{de}\}$ del. et interl.

25 qui $\{\mathrm{m}>\mathrm{n}\}$ corr.

26 copulantis em.] copulansis

27 copulare $e m$.] copulane

28 Agustín, De Trinitate 8.10,14.

29 Aristóteles, Éticas 8.1 .

30 Theseo $\mathrm{em}$.] protheu

31 La relación de amistad entre Teseo y Piroteo o Pirítoo era proverbial. Véase Homero, Odisea, 21.195-305 y Ovidio, Metamorfosis, 12.210. La narración más detallada del inicio de su amistad se encuentra en Plutarco, Vidas Paralelas, 31 (Teseo), 1 y 2.

$32 \operatorname{dict}(\mathrm{e}>\mathrm{i})$ post corr.

33 Para el episodio de Salmacis y Hermafrodito, cf. Ovidio, Metamorfosis, 4.285-388.

$34\{\mathrm{~d}\}$ uos del.

35 interl.

$36\{a>$ e $\}$ ço corr.

$37\{$ e $\}$ vnju del.

SCRIPTA, Revista internacional de literatura i cultura medieval i moderna, núm. 10 / desembre 2017 / pp. 1-25 ISSN: 2340 - 4841 doi:10.7203/SCRIPTA.10.11072 
e ajustau. Car cert, vós, Amor, copulàs, unís e transformàs ${ }^{38}$ aquell gran déu Apol lo, invisible e inmortal, ab la humanal natura, qui és mortal e visible $;^{39}$ e vós unís e ajustàs l'ome mortal ab lo gran déu de mor e de inmortal vida, l'ome aveu fet Déu, e Déu aveu fet home per unió inseparable e ypostàticha e personal, per comunicació de perlas e propietats alterutres. Per què diem: «Amor quos unit, nemo disiunge valeț. ${ }^{40} \mathrm{E}$ vós, Amor, conglutians ${ }^{41}$ l'ànima de ${ }^{42}$ Sichem en la amor de Dirta (Genesis 34). ${ }^{43} \mathrm{E}$ vós, Amor, conglutians l'amor de Jonatàs ab l'ànima de David, e tot per amor fina (Primo Regum 15) ${ }^{44}$. Unde: «Merito veteres vos ${ }^{45}$, si ${ }^{46}$ Amorem, figurabant admodum pulcherrimi iunenis quattuor preciosorum lapidum coronam coronatum, induti tunica coloris niridit in cuius fimbriis escribebatur per girum: VITA ET MORS, YEMS ET ESTAS, LONGE ET PROPE, cor buius apertum», ${ }^{48}$ a denotar que qui bé ama, jamés

38 Aunque extraña por su terminación verbal, la lectura es muy clara tanto en esta tríada verbal como en la que se encuentra en la línea siguiente. Mantenemos por prudencia la lección del manuscrito.

39 La conexión entre Apolo y Jesucristo es conocida en toda la Patrística. Felip de Malla también reflexiona sobre la similitud en diversos pasajes de su obra, como por ejemplo en el capítulo 2 de la primera parte de su Memorial del pecador remut: «O déu Apol lo! No dic tu, aquell fals déu strany de la dèlphica illa, mas tu, ver sol del ventre virginal, sol dels elets transcendents, divinal e ensemps humanal, tu, qui trespasses facúndia tebana e als murs e als bruts prestes laor vocal, e fas lo sol regirar per la spera, il luminant tot ço que pot mirar e ton sagell possist dins nostra cera» (Balasch 1981: 114).

40 Citado de manera muy parecida por Juan de Salisbury, Entheticus de dogma philosophorum, 33 (Patrologia Latina $=$ PL vol. 199, col. $\left.979^{\mathrm{a}}\right)$ : «Si vis nulla potest disiungere, quos amor unit / Verus philosophus non erit absque Deo», aunque posiblemente proceda de una fuente secundaria. Cf. también Entheticus maior, 2, par. 45, vv. 651-652 (Entheticus maior et minor, ed. Jan van Laarhoven, 1987, vol. 1, Leiden: Brill, p. 147).

41 Lectura incierta, tanto en este caso como en el que se encuentra pocas palabras más tarde. El significado es claro: 'entrelazando estrechamente', del verbo latino congLuTiNo.

$42\{s\}$ de del.

$4334 \mathrm{em}.] 3^{\circ} 4^{\circ}-\mathrm{Gn} 3,4$.

$441 \operatorname{Re} 15$.

45 interl.

$46 \operatorname{si}\{\mathrm{n}\}$ del.

47 uiridi $e m$.] vndidi

48 Se trata de una versión imperfecta de la figura de la amistad en la descripción del dominicano Robert Holcot (o en una fuente secundaria parecida, como las Gesta Romanorum), que parte una imagen de Fulgencio: «Pictura Amoris sive Amicitia: Narrat Fulgentius in quodam libro De gestis romanorum quod Romani verum amorem sive veram amicitiam hoc mode descripserunt, scilicet: Quod imago amoris vel amicitiae depicta erat instar iuvenis cuisdam valde pulchri, induti habitu virido. Facies eius et caput discooperta erant sive nudata, et in fronte ipsius erat hoc scriptum: HYEMS ET AESTAS. Erat latus eius apertum, ita ut videretur cor, in quo scripta erant haec verba: LONGE ET PROPE. Et in fimbria vestimenti eius erat scriptum: MORS ET VITA. Similiter ista imago habebat pedes nudos et cetera». Cito de Renedo (1990-91: 56).

SCRIPTA, Revista internacional de literatura i cultura medieval i moderna, núm. 10 / desembre 2017 / pp. 1-25 ISSN: 2340 - 4841 doi:10.7203/SCRIPTA.10.11072 
oblida. Car escrit és (Prouerbiorum 17): "Qui amicus est, omni tempore diligit». ${ }^{49}$ "Veus — diu Amor— ${ }^{50}$ què són yo. [146v]

[4]»Mas demaneu ${ }^{51}$ e yo d'un vench e procehesch. Un vos responch que procehesch de complacença; visch e servesch de dolça benvolença; vaig-me'n del món, muyr e pertesch, per gran desconexença».

Dich yo: «Amor: e d'on ve complacença?» Respon Amor: «Ve de senblança; si bé veriant ${ }^{52}$ ve de conformitat de qualitats e de virtuts ensemps. Cor escrit és (Ecclesiastici, in capitulo 13): «Omne anima ${ }^{53}$ diligit sibi simile et omnis homo proximum sibir; $;{ }^{54}$ et VIII Ethicorum: ${ }^{55}$ "Equalitas et similitudo amiciciam faciunt»; ${ }^{56}$ et Tullius ( $3^{\circ}$ De officis): «In bonis solum est amicia, in malis uero fictio»; ${ }^{57}$ et libro De amicicia: «Virtus amiciciam gignit, nec sine virtute dilectio est», ${ }^{58}$ et in $2^{\circ}$ Rethorice: «Bonorum est amare bonos». ${ }^{59}$ Quare dicit amorosus ${ }^{60}$ Deus (Proverbiorum VIII): ${ }^{61}$ «Diligentes me diligo», ${ }^{62}$ et Canthicorum, secundo: «Dilectus meus michi, et ego illìr. ${ }^{63} \mathrm{E}^{64}$ açò per tant com Amor proceheix de mútua complacença e de conformitat calitativa he virtuosa.

49 Prov $17,17$.

50 amor $\{$ q que $\}$ del.

51 demaneu $e m$.] demanen

52 Lectura incierta.

$53\{$ ail $\}$ animal del.

$54 \operatorname{Sir} 13,19$.

$55\{$ ethil\} ethicorum del.

56 La formulación exacta de las Éticas de Aristóteles (8.7.3) es: «Sit igitur magna distantia et imparitas impedimento est amicitiae, ergo paritas seu similitudo et aequalitas, quo fuerit major, eo magis et amicitiam conglutinabit et continebit.» Sin embargo aquí la cita procede de Tomás de Aquino, Tabula libri Ethicorum, 1.16: 45: «Quod amicicia est quedam equalitas et similitudo».

57 Parece, en realidad, una adaptación de Laelius 18: « nisi in bonis amicitiam esse non posse».

58 En el Laelius, 20, se lee: «sed haec ipsa virtus amicitiam et gignit et continet nec sine virtute amicitia esse ullo pacto potest».

59 Aristoteles Latinus 31.1-2: Rhetorica, vol. 17, ed. Lorenzo Minio-Paluello, Brill, 1986, p. 230 [Rhe 2.4-5]: «Et totaliter eos qui valde amatores amicorum et non derelinquentes; maxime enim amant bonorum amare bonos».

$60 \mathrm{em}$. amorous

61 viii $\{j\}^{\circ}$ del.

62 Prov 8,17.

63 Cant 2,16.

$64\{\mathrm{e}\} \mathrm{E}$ del.

SCRIPTA, Revista internacional de literatura i cultura medieval i moderna, núm. 10 / desembre 2017 / pp. 1-25 ISSN: 2340 - 4841 doi:10.7203/SCRIPTA.10.11072 
[5] »Are us diré — diu més, Amor- e yo de què 'm mentenc e visch. Car vull que sapiats yo visch o viu de tres plasents viandes, so és: ex adequacione animorum, ex reuelacione secretorum, ex comunicacione bonorum. Car axí com Tul li diu que amor o amícicia «est idem uelle et idem nolle in rebus honestis inter amicos», ${ }^{65}$ apar que Amor les ànimas e persones amants aguala. E més, diu ell: «Maxime est in amicicia superiorem parem esse inferiori», unde: «Amicus quasi animi custos ${ }^{66}$ dicitur. Et ubi unus amicorum uellet dominari oportet amiciciam infingi》, en tal manera que, axí com diu Ovidi (in primo Methamorphoseos): «Non bene conueniunt, nec in una sede morantur magestas et amons. ${ }^{67}$ Per què diu l'Aristòtil, in VIII Ethicorum, capitulo CI, [147r] quod: «Amicicia dicitur equalitas». ${ }^{68}$ Primerament, que tant deus tu amar com vols ésser amat. E aquesta és la ley de amor e amicícia, segons diu Tul li (in $2^{\circ}$ De Officis, capitulo ${ }^{69}$ 179), quod: «Tantum debet quis diligere, quantum credit diligi;; et Seneca (Epistola octana): «Mostrabo tibi magnum amatorem sine medicamento, sine ${ }^{70}$ hec uis et sine quocumque benificios. ${ }^{71} \mathrm{E}$ parla de aquells qui desigen ésser amats, per què diu ell: «Si uis amari ama; longe melius enim est amicum facere quam habere, quemadmodum pictor prius delectatur in ${ }^{72}$ pingendo quam in pictiones. ${ }^{73}$

[6] »Viu, enaprés — diu més Amor-, ex renelacione secretorum. Car diu Sèneca (2º libro Epistolarum, epistola ultima): «Si aliquem amicum existimas cui non tantum credas quantum tibi, uehementer erres», et idem: «Omnia cum amico deliberare debemus, sed de ipso prius». ${ }^{74} \mathrm{E}$ açò us signifique lo cor ubert de Amor. Per què diu lo Tul li, De amicicia: «Excepta sapientia nichil melius a Diis in mortalibus datum est» homini

65 Tomás de Aquino, Summa 1.42.3: «Ubi vera amicitia est, ibi idem velle, et idem nolle, tanto dulcius, quanto sincerius». En realidad es una pasaje de Salustio, De Catilinae coniuratione, 20: «idem velle atque idem nolle, ea demum firma amicitia est». También en las Éticas 8: «Quod amicitia te exigit amicitiam, et ideo amicorum est ídem velle, et ídem nolle, nec amicus habet voluntatem propiam sed amici».

66 custos em.] equs. - Todo el pasaje podría proceder de Cicerón, aunque quizás aquí se cita a través de Gregorio, XL Homiliarum in Evangelia II, Hom. 27.4 (PL vol. 176, col. 1207): «Amicus enim quasi animi custos vocatur», o Isidoro, Etymologiarum, libro X 'De vocabulis', 176: «Amicus per derivationem, quasi animi custos».

67 Ovidio, Metamorfosis, 2.846-847.

68 Probablemente la fuente sea Tomás de Aquino (Tabula libri Ethicorum 1.16.27): «Quod amicicia dicitur equalitas et maxime ei que bonorum».

$69 \mathrm{ca}^{\circ}\{\}$ post corr.

$70\{$ siu $\}$ sine del.

71 Versión muy deturpada de Ad Lucilium 9.6, de Séneca: «Ego tibi monstrabo amatorium sine medicamenta, sine herba, sine ullius veneficae carmine: si vis amari, ama».

72 in $\{\mathrm{p}\}$ del.

73 Continuación de la cita anterior de Séneca: «Si vis amari ama; longe melius enim est amicum facere quam habere; quemadmodum pictor prius delectatur in pingendo quam in pictione».

74 Séneca, Ad Lucilium, 1.3.2 ambas citas.

SCRIPTA, Revista internacional de literatura i cultura medieval i moderna, núm. 10 / desembre 2017 / pp. 1-25 ISSN: 2340 - 4841 doi:10.7203/SCRIPTA.10.11072 
amicicia. ${ }^{75}$ "Quid enim dulcius quam habere amicum, cum quo omnia audeas sic loqui, ut tecum?»; ${ }^{76}$ et Ambrosius (De officis, libro $3^{\circ}$ ): «Solacium nite hominis est, ut habeas cui pectum tuum aperias: cui archana commitas et collores tibi fidelem et uirum qui in prosperis congratuletur et in tristibus condoleat et in persecucionibus consoletums. ${ }^{77}$ Etprous, ${ }^{78}$ in Epistola Ad Demetriadem virginem: «De amicicia ${ }^{79}$ [omnis tolenda est suspicio] ${ }^{80}$ Et sic cum amico, quasi cum altero se, loquendum».

[7] »Encara viu — diu ${ }^{81}$ més Amor — ex comunicacione temporalium bonorum proater ${ }^{82}$ et laborum. Car ${ }^{83}$ axí com diu lo gran moral sent Gregori: «Probacio dilectionis est exibicio operis»; ${ }^{84}$ et Cassiodorus, in Epistola, diu quod: «Neccessitas amicum probat, et exbibire subuencionis amoris elucidant tormentum no [n] separat, labor $[147 \mathrm{v}]$ non lassat, thesaurus non superat, alienus amor non pertorbat); ${ }^{85}$ et Isidorus (liber $3^{\circ}$ De Sententiae) dicit quod: «In prosperitate incerta est amicicia, nescitur enim utrum persona aut felicitas diligatun», ${ }^{86}$ nam tempore felici multi dicunt amici. Per què diu lo Savi: ${ }^{87}$ "Qui amicus est, in angustiis comprobatun»; ${ }^{88}$ e l'Aristòtil (in

75 Cicerón. Laelius, 20.

76 Versión pseudo-senequiana (Mor. 20) de un paso de Cicerón (Laelius 6,22): «quid dulcis quam habere quicum omnia audeas sic loqui tecum?», también formulado por Séneca (Epis. 3.2): «tam audaciter cum illo [amico] loquere quam tecum».

77 En realidad circuló como pseudo-Bernardo, en una versión con algunas diferencias (De ordine vitae 3.10; PL vol. 184, col. 567bc): «Magnum enim huius vitae solatium est, ut habeas cui pectus tuum aperias: cum quo arcana participes: cui committas secreta cordis tui, ut ames et sequaris eum: qui tibi paterna pietate in tristibus compatiatur, in persecutionibus adhortetur, et in prosperis gratuletur».

78 Lectura incierta.

79 ami $\{$ cicia $\}$ cicia del.

80 Espacio en blanco en el manuscrito, que colmamos con la cita la epístola correspondiente de san Agustín: Epistulae, 72 [Domini vere sancto et beatissimo papae Augustino Hieronumus], par. 2.

$81\{$ mes $\}$ diu del.

82 Lectura incierta.

83\{\} car post corr.

84 Gregorio, Lectio S. Evang. Sec. Ioan, 24,23-31,1; Hom. 30 (PL vol. 76, col. 1220c).

85 Cita no localizada, aunque toda la tradición remite a una epístola de Casiodoro para este pasaje.

86 Isidoro, Sententiae 3.29.1 (PL vol. 83, col. 702d): «nam in prosperitate incerta est amicitia, nec scitur utrum persona an felicitas diligatur».

87 Espacio en blanco en el manuscrito tras Savi.

88 Prov $17,17$.

SCRIPTA, Revista internacional de literatura i cultura medieval i moderna, núm. 10 / desembre 2017 / pp. 1-25 ISSN: 2340 - 4841 doi:10.7203/SCRIPTA.10.11072 
ИIII Etbicorum), quod: «In comunicacione omnis amicicia»; ${ }^{99}$ et Sèneca (in Proverbiis): ${ }^{90}$ "Succurrere debemus paupertati amicorum, ymo occurrere»; ${ }^{91}$ et Boecius (De consolatio, IIII', prosa ultima, infra ${ }^{92}$ ): «Preciosissimum genus diniciarum inuenisti, si ueros amicos inuenistì ${ }^{93}$, ut loquitur lo Savi, qui diu: ${ }^{94}$ "Qui inuenit amicum, inuenit tesaurum», ${ }^{95}$ et: «Amico fideli nulla comparacion; ${ }^{96}$ o diu lo Tul li ${ }^{97}$ És lo bé de amor o amicícia, cor: "Amicicia abssentes adsunt egentes ${ }^{98}$ habundant et imbecilles ${ }^{99}$ ualent, et quod difficilius est mortui uiuunt», ${ }^{100}$ et quidam dicunt: «Vera amicicia ymo et amor eodem modo respicit amicum dinitem et mendicum, debilem et fortem, sanum et egrum, bumilem et sublimems. ${ }^{101}$ Veus, diu Amor, yo de què visch.

[8] »Mas demanau yo què sé fer de mon art e offici. Unt vos responch que mon art és nodrir e provehir, servir e argüir. Car, sert, amor nodrex los animals; amor servex e provaheix ${ }^{102}$ los corals; e amors corregex ${ }^{103}$ lo amat de sos mals. Per què diu Sèneca (De moribus): «[Amicos secreto admone] palam lauda»; ${ }^{104}$ mas pus fort diu sent Ambròs (3 libro De officis): «Si quid vicii in amico cognoueris, corripe primo

89 La cita original de la Ética a Nicómaco en su versión latina reza: «Et prouerbium recte ea quae sunt amicorum, communia dicit esse; amicitia namque in communicatione societate quam consistit» (Basileae : ex officina Ioan. Oporini, Anno 1548, vol. 3, p. $65=8.9$ ), aunque en nuestro texto parece proceder de la versión sucinta de Tomás de Aquino, Sententia libri Ethicorum, 8, 9, 1; 7 («Omnis amicitia in communicatione quadam consistit; omnis autem communicatio reducitur ad politicam»); y también en sentido parecido en 8.9.1.12 y 8.12.1.6. También en Summa Theologiae, II-II.25.3.28.

90 inpro $\{$ ver $\}$ uerbijs del.

91 Proverbia 50: «Succurre paupertati amicorum, immo succurre cuiusvis».

92 Lectura incierta.

93 Boecio, Consolatio 2, prosa 8, párrafo 7: «Desine nunc et amissas opes quaerere, quod pretiosissimum divitiarum genus est, amicos invenisti».

94 Espacio en blanco en el manuscrito tras diu.

$95 \operatorname{Sir} 25,12$

$96 \operatorname{Sir} 6,15$.

97 Espacio en blanco en el manuscrito tras Tul $l i$.

$98\{\mathrm{~g}\}$ egentes del.

99 imbecilles $\mathrm{em}$.] becilles

100 Laelius 7 y 23.

101 Pedro de Blois, De amicitia Christiana et de charitate Dei et proximi, 1.14 (PL vol. 207, col. 885a): «Vera amicitia eodem oculo respicit amicum divitem et mendicum, fortem et debilem, sanum et infirmum, humilem et sublimem».

$102\{$ pro\} prouaheix del.

$103\{$ s on $\}$ corregex del.

104 Restituimos la oración completa a partir de los Proverbia de pseudo-Séneca: «12. Amicos secreto admone, palam 
occulte; quod si non audiet, corripere palam. Amicum errantem turpia quidem widere, aut de amico audire pudett; ${ }^{105}$ Tullius, De amicicia: «Haec est lex amicicie, ut neque rogemus res turpes, neque rogari faciamus». ${ }^{106}$ Per què dix lo Savi: [148r]: ${ }^{107}$ «Meliora sunt unlnera diligentis quam osculo odientis». ${ }^{108} \mathrm{E}$ lo amorós Déu (Proverbiorum 3 et Apochalipsis 3 capitulis): «Quos ego amo, arguo, corrigo et castigo». ${ }^{109}$

[9] »Veus — diu Amor- yo què sé fer e quin és mon art e mon offici e de què servesch. D’on per los fols són mal graïda. Unt per açò: «Qui oderunt me, diligunt mortem» (Proverbiorum, $8^{\circ}$ capitulo). ${ }^{110} \mathrm{E}$ per ço me'n vaig del món com $^{111}$ a bandeyada; muyr e pertesch per gran desconexença; d'on en loch meu se complanyen, en loch meu, amadors, etc.»

[10] Lo primer és qui 's ret ${ }^{112}$ falló, nostre senyor l’amorós déu. Lo segon és en Castelló, home d'onor, qui 's mossèn Barthomeu. Lo tercer és d'est papelló a la rredor tothom arreu».

[11] Diu lo primer:

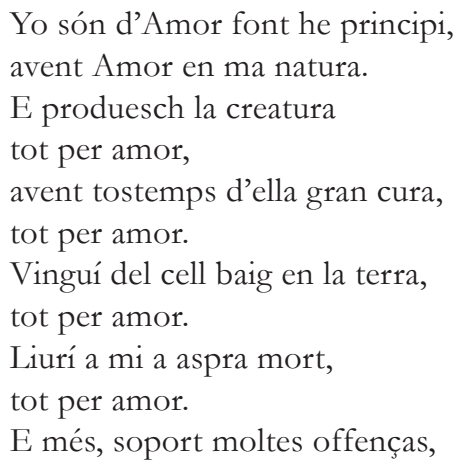

lauda».

105 Ambrosio, De oficis ministrorum, 3.22127 (PL vol. 16, col. 180c): «Sane si necesse sit dicere testimonium, si quid in amico vitii cognoverit, corripere occulte; si non audierit, corripere palam. Sunt enim bonae correptiones, et plerumque meliores quam tacita amicitia. Et si laedi se putat amicus, tu tamen corripe; et si amaritudo correctionis animum eius vulneret, tu tamen corripe, ne verearis: Tolerabilia sunt enim amici vulnera, quam adulantium oscula (Prov. XXVII, 6). Errantem igitur amicum corripe, innocentem amicum ne deseras».

106 Lael. 40: «Haec quidem est lex amicitiae, ut neque rogemus res turpes, neque rogati faciamus».

107 Espacio en blanco innecesario en el manuscrito, quizás provocado por el cambio de folio.

108 Prov 27,6.

109 Ap 3,19.

110 Prov 8,36.

$111\{\mathrm{com}>\mathrm{com}\}$ del. et interl.

112 ret $\mathrm{em}$.] net

SCRIPTA, Revista internacional de literatura i cultura medieval i moderna, núm. 10 / desembre 2017 / pp. 1-25 ISSN: 2340 - 4841 doi:10.7203/SCRIPTA.10.11072 
Sadurní Martí. La sentencia del certamen poético de Sant Just (1438): edición y estudio preliminar

\author{
tot per amor. \\ E són tot prest a perdonar \\ e a dar a l'om felicitat, \\ tot per amor.
}

Tant que ya per amor fer ${ }^{113}$ pus ${ }^{114}$ no resta, per tot açò de l'hom no vull sinó amor e coneixença (Deuteronomio, capitulo $X^{\circ}$ : «Et nunch, Israel, quid Dominus tuus petit a te, nisi ut diligas eum ach seruias»; ${ }^{115}$ e avie dit (Michee $\left.V^{o}\right):{ }^{116}$ «Diliges, Dominum Deum tuum»). ${ }^{117}$ Pare, Fill e Sant Spirit, un sol Déu en ${ }^{118}$ natura ex corde tuo, com a ton creador, per fe tendent en Ell e per l'enteniment; et ex tota anima tua, com a ton governador, per memòrie e esperança Ell ${ }^{119}$ recollent; [148v] et ex tota fortitudine tua, com a ton redemptor, $\mathrm{e}^{120}$ per la $\mathrm{a}^{121}$ voluntat, amor $\mathrm{e}^{122}$ caritat ves Ell tot fervent.

Sent Agustí (in libro De cathetizandis): "Ama amorem illius qui amore tui amoris de celis descendit in uterum Virginis, qui amorem suum tuo amori copulavit, bumiliando se, te sublimando, et coniungendo lumen sue diuitiarum limo tue mortalitatis». ${ }^{123}$ Preterea, Bernardus (Militia de amore Dei): "Vultis miqui ${ }^{124}$ a me audire, quare et quomodo diligendus est Deus? Et ego dico quod causa diligendi Deum, Deus ${ }^{125}$ est: modus, sine modo [...] causam

113 interl.

114 pus $\{$ fer $\}$ del.

115 Dt 10,12.

116 Después de $V T^{\circ}$, un espacio en blanco.

117 Dt 6,5.

118 en $\mathrm{em}$.] est

$119\{$ a $\}$ ell del.

120 interl.

121 la $\{$ amor $\}$ del.

122 interl.

123 Este pasaje aparece atribuido genéricamente, en toda la tradición, a esta obra agustiniana, aunque no se ha podido localizar en esa obra.

124 Lectura incierta.

125 deum $\{$ deus est $\}$ deus del.

SCRIPTA, Revista internacional de literatura i cultura medieval i moderna, núm. 10 / desembre 2017 / pp. 1-25 ISSN: 2340 - 4841 doi:10.7203/SCRIPTA.10.11072 
dico Deum propter seipsum [diligendum]; vel quia nibil justius uel fructuosius nibilque dignius»; ${ }^{126}$ et, ${ }^{127}{ }^{\circ}$ Super Cantica Canticorum: «Diligendus est Deus quia ipse dilexit nos dulciter, sapienter e fortiter. Dulciter quidem dilexit nos in nostram naturam asumpsit; sapienter quia culpam nostram destruxit; et fortiter quia Inimicum nostrum interfecit et mortem pro nobis sustinuit». ${ }^{128}$ Unde ipse: «Maiorem dilectionem banc nemo habet, ut animam suam (id est uitam corporalem) ponat ${ }^{129}$ amicis suis». ${ }^{130}$ Unde: «Fortiter est ut mors dilectio». ${ }^{131}$ Aprèn, diu sent Bernat, de amar ten amorós Déu qui tant te ama. Aprèn-lo de amar dolçament per amor, prudentment sens error e fortment sens dolor (per què diu lo proverbi: Ama qui t'ama e respon a qui t clama, car tant és amar e no ésser amat, com és respondre e no ésser cridat), e sobre totes coses com sie summum bonum (car diu sent Agusti1 ${ }^{132}$ que no sab d'amar qui totes coses ama), e per amor d'ell matex (cum sit a se et omnia sunt ab eo) com a principi e fi de totes coses, alpha et omega (Apochalipsis, $1^{\circ}$ capitulo). ${ }^{133}$ i Set, heu, ab quant dol e complanta avem a dir se ${ }^{134}$ clame e s complany d'amor l'amorós Déu per la desconexença [149r] qui és en l’ome falç e desleal amador, ingrat e obliviós de tots los actes de transcendent amor e obres amoroses per lo amorós Déu ves ell ten greument exercides! Per què 's complany l'amorós Déu, dient, ab lo propheta ${ }^{135}$ (Malechie, $1^{\circ}$ capitulo): «Dilexi vos —ho, desconexentes persones!-, et dixistis: in quo dilexisti nos?»; ${ }^{136}$ quaig qui vulle innuir què e com nos hi va lo cor, ans ${ }^{137}$ desamau a mi amant les creatures, d'on incorreu lo crim de leze magestat, per peccat e malesa, avertint-vos de mi, qui són lo creador e bé incomutable, e convertiu al món per amor ambriague ha fols desconexents e fols amadós, etc.

126 Pasaje muy transformado del De diligendo Deo (1.1; PL vol. 182, col. 974a-975a), cuyo texto original reza: «1. Vultis ergo a me audire, quare et quomodo diligendus sit Deus? Et ego: Causa diligendi Deum, Deus est; modus, sine modo diligere [...]. Ob duplicem ergo causam Deum dixerim propter seipsum diligendum: sive quia nihil iustius, sive quia nil fructuosius diligi potest)».

127 Después de et, un espacio en blanco para incluir el nombre del autor, sin duda todavía Bernardo.

128 Cita secundaria de Bernardo de Claravall (Sermones in Cantica Canticorum 20.3; PL vol. 183, col. 868a): «Dilexit autem dulciter, sapienter, fortiter. Dulce nempe dixerim, quod carnem induit; cautum, quod culpam cavit; forte, quod mortem sustinuit».

129 ponat $\mathrm{em}$.] det quis pronat

130 Jn 15,13. Sigue un espacio en blanco en el manuscrito.

131 Ct 8,6. Tras dilectio sigue la lectura incierta Dei a patre deo christi.

132 aug\} agusti del.

133 Ap 1,8 .

134 se $e m$.] se se

$135\{\mathrm{ph}\}$ propheta del.

$136 \mathrm{Mal} 1,2$.

137 ans $\{$ vo $\}$ del.

SCRIPTA, Revista internacional de literatura i cultura medieval i moderna, núm. 10 / desembre 2017 / pp. 1-25 ISSN: 2340 - 4841 doi:10.7203/SCRIPTA.10.11072 
Et super hoc parla sent Agustí, dient per esta forma: «Summa peruersitas homini ${ }^{138}$ est frui utendis et uti fruendis». ${ }^{139} \mathrm{E}$ com fruir sia o acte de fruÿció (alicui amore in herrore propter se tantum), e aquest e açò sie tant solament Déu (e uti sic aliqui assumere ad facultatem uoluntatis propter idem tui sumendum est), de açò se segueig que a tots aquells amorosos qui amen més alguna cosa ${ }^{140}$ que Déu, e dexen Déu e servexen la creatura, e aquesta és ${ }^{141}$ la major perversitat que pot ésser en la creatura e persona. E si tu dius que ames més Déus que res, provaré que no fas: ans ames més la cosa per la qual tu més fas e actes e senyals d'amor demostres. (Are la pràticha sia remesa a quiscú.) E pus fort te diré: que si tu ames Déu més per lo bé que n'esperes, que no per amor d'ell, uses d'ell e serveix a tu matex, e fas de Déu ton servidor, car no l'amas per sola amor sua, mas ${ }^{142}$ per amor de tu. E de açò és Déu felló sensa peccat en ell. Cor ha dit sent [Jeroni], ${ }^{143}$ Ad Eliodorum Episcopum: «[Debet amore laesus irascì). ${ }^{144}$ Igitur diu l'a[149v]morós sent Johan (prima Iohannis $\left.4^{\circ}\right):{ }^{145}$ "Diligimus et nos Deum, ${ }^{146}$ quoniam ipse prior dilexit nos), unt per ço com no u fem, se complany ell d'Amor. E aquest és lo primer qui fa sa complanyença.

[12] Lo segon amorós qui ‘s complany de Amor es mossèn Castelló, lo quall, pus ha edat perfeta e complida, parlarà ell matex, e farà sa complanta.

[13] Mas lo tercer e final és qui de Amor se complany, en nombre singular posant la multitut jus aquest papelló. Per tots alarredor serà tot hom arreu, car axí veig e hoig qu'és d'amós com de armes, e plets e jochs: car los més veig que 's clàman. E crech bé que quescú vol ésser avantayós en art d'amor, e los més amen per lur barat. Per què ya açò no deu aver nom amor, ${ }^{147}$ mes enguan e tamor, car voler ésser amat e no amar és contra ley d'amor e amicícia. E los amadós vuy, uoce tantum, et non ve són amadós ne amen per lo bé honest, lo quall és propi objecte d'amor, ans amen més per lo bé a ells sobreútil e delitós, axí com los minyons, hon tant dura l'amor com los fareu complacensas, e no pus.

138 \{est $\}$ homini del.

139 Agustín, De diversis quaestionibus, 30. Seguramente citado aquí a través de Tomás de Aquino, Summa theologiae, I-II, 71.6.13.

$140 \cos ($ a) post corr.

141 post corr.

$142\{\mathrm{~m}\}$ mas del.

143 Añadimos la información que falta en el espacio en blanco del manuscrito.

144 Pasaje corrupto en la copia. En el manuscrito se lee de amor(e) lemus ynati delegatus. Restituimos la lección de Jerónimo. $145 \mathrm{Jn} 4,19$.

146 Tras Deum, eliminamos E gratia non.

$147\{$ de $\}$ amor del. 
$\mathrm{E}^{148}$ diu sent Ambròs (libro $3^{\circ}$ De Officis): «Virtus est amicicia, non ques[t]us». ${ }^{149}$ Qui ama, donchs, l'altre per amor o per esguart de altre cose que aquell no és, no ame aquell, mas la cose per la quall lo dit ama. E aquesta amor és dita baratera, falça e traffaguera, de la qual los més se clamen, se dolen e s complanyen. $\mathrm{E}$ ab tot açò, $\operatorname{los}^{150}$ més hi van ${ }^{151}$ derrera, e seguexen son penó e bandera. E no aver esguart als qui coralment amen és gran ingratitut e gran desconexença, car lo major servey que hom pot fer a l'altre és amar de cor e per sola amor sua [... ${ }^{152}$ amem tots lealment, fina e vertadera, [150r] a ffi que digue quiscú verteder amorós (Canthicorum, in 20:153 "Ffulgite me floribus, stipite me malis [id est: condensate criminalliter replete me ramis cum pomis et fructibus, admodum infirmo], quia amore langueo»): ${ }^{154}$ car jo languesch per gran excés ${ }^{155}$ de leal amor. E ab lo nom de Déu oyam vostres complantes, etc.

[14] E ja que Amor, a nós ten necessàrie axí com dit avem, per gran falta de lealtat e per ${ }^{156}$ desconexença sia vuy del món quaix tot ${ }^{157}$ expulsa, res tant no ss bastant tornar-la en los mortals e 'n nostra pau e treva, com és apte e dolç officiar de llengua (car escrit és: «Linga placabilis lignum uite»:; ${ }^{158}$ e en altre part: «Linga suanis mitigat inimicos et multiplicat amicos»). ${ }^{159} \mathrm{E}$ lo gran déu d'amor e de inmortal vida ja veiges ${ }^{160} \mathrm{com}$ belament à decorats e insignits e dotats los presents mossenyors de tal do e suffragi are per deos(?) $)^{161}$ a mi se renoven $\operatorname{los}^{162}$ setgles [... ${ }^{163}$ los sapients, qui éran Sòcretes, Plató, Porfiri, e los altres, los quals a present anomenar no affretura.

$148 \mathrm{E} e m.] \mathrm{A}$

149 questus em.] quesus — Ambrosio, De officis, 3.22.133.

150 los em.] les

151 va $\{\mathrm{m}>\mathrm{n}\}$ corr.

152 Espacio en blanco de casi una línia en el manuscrito.

$153\left\{\mathrm{c} 3^{\circ}\right\}$ in $2^{\circ}$ del.

154 Ct 2,5 .

155 acces\} exces del.

$156\{$ per\} $(\wedge \mathrm{e})$ e per del. et interl.

157 tot $\{a\}$ del.

158 Prov 15,4.

$159 \operatorname{Sir} 5,6$.

160 post corr.

161 Lectura incierta: $\{$ dons $>$ deos $\}$ del. et interl.

$162\{\mathrm{~s}\}$ los del.

163 Posible laguna.

SCRIPTA, Revista internacional de literatura i cultura medieval i moderna, núm. 10 / desembre 2017 / pp. 1-25 ISSN: 2340 - 4841 doi:10.7203/SCRIPTA.10.11072 